Available online at www.eccomasproceedia.org

Eccomas Proceedia COMPDYN (2019) 633-650

\section{ECCOMAS}

\section{Proceedia}

COMPDYN 2019

$7^{\text {th }}$ ECCOMAS Thematic Conference on Computational Methods in Structural Dynamics and Earthquake Engineering

M. Papadrakakis, M. Fragiadakis (eds.)

\title{
THE CORNER FAILURE IN A MASONRY BUILDING DAMAGED BY THE 2016-2017 CENTRAL ITALY EARTHQUAKE SEQUENCE
}

\author{
Luca Umberto Argiento ${ }^{1}$, Alessandra Maione ${ }^{1}$, Linda Giresini ${ }^{2}$ \\ ${ }^{1}$ Department of Structures for Engineering and Architecture, University of Napoli Federico II \\ Via Forno vecchio, 36, 80134, Napoli, Italy \\ lucaumberto.argiento@unina.it,arch.maione@gmail.com \\ ${ }^{2}$ Department of Energy, Systems, Territory and Constructions Engineering, University of Pisa \\ Largo Lucio Lazzarino, 1, 56100, Pisa, Italy \\ linda.giresini@unipi.it
}

\begin{abstract}
Although still poorly investigated, the failure of corners is a frequent event in masonry buildings and clearly recognizable in the aftermath of a seismic event. It is characterized by the formation of a masonry wedge, mainly due to the thrust of roof elements in addition to inertial forces, and it generally involves rocking-sliding motion along the cracks on the interlocked orthogonal walls. In this paper, the case study of the corner failure in a masonry building located in Visso (Italy) is analyzed. The building was seriously damaged by the seismic events of August 24th, 2016 and October 26th and 30th, 2016. In particular, one of the free corners at the first storey completely collapsed. The seismic capacity with respect to the onset of this failure mode is analyzed by means of a refined macro-block model and by adopting the linear kinematic approach of limit analysis, accounting for frictional resistances and the thrust of roof elements. The key aspect of the proposed approach is the introduction of a criterion to evaluate the contribution of the actual frictional resistances depending on the inclination angles of the crack lines. Moreover, the loads transmitted from the roof to the walls are defined by assuming simplified static conditions according to the typology of the hipped roof. Lastly, the achieved results are compared to the seismic demand obtained by adopting the Italian Technical Standards for Constructions, both the earlier version (2008) and the current one (2018), together with that obtained using in situ recorded floor accelerations.
\end{abstract}

Keywords: Masonry Corner, Rocking-Sliding Mechanism, Frictional Resistances, Kinematic Approach, Limit analysis, Seismic Demand.

ISSN:2623-3347 C 2019 The Authors. Published by Eccomas Proceedia.

Peer-review under responsibility of the organizing committee of COMPDYN 2019.

doi: $10.7712 / 120119.6945 .19268$ 


\section{INTRODUCTION}

The vulnerability to the local failure mechanisms frequently characterizes the behavior of masonry buildings, when exposed to seismic actions directed orthogonally to the involved walls. Such a vulnerability is exacerbated in case of irregular buildings, where torsional modes increase the seismic demand in the peripheral walls [1][2]. In this case, the crack pattern can lead to the separation of portions of the walls which exhibit an autonomous behavior in the out-of-plane response; local failures, on the other hand, can imply severe damage in the whole building, triggering an extensive chain of progressive collapses.

The systematic survey of the seismic damage suffered by masonry buildings allowed recognizing typical out-of-plane failure mechanisms on the base of their recurrent crack patterns [3]-[6]. In particular, two main classes of these mechanisms may be identified: simple or complex rocking mechanisms of walls, or portions of walls, are usually related to weak connections with the rest of the building, while flexural mechanisms are characterized by the development of the arch effect (horizontal or vertical).

In this paper, a case study is presented concerning the rocking-sliding failure occurred at the corner of a masonry building in an Italian town during the 2016-2017 Central Italy seismic sequence. This type of mechanism is still poorly investigated [7]-[9], although it frequently occurs, mainly when the constructive typology of roof can cause thrusting actions in addition to seismic forces. The reference to a case study building, on the other hand, can be useful to verify the reliability of the proposed analytical models in predicting the onset of the failure mechanisms and their evolution until the complete collapse. The relevance of the consequences of local mechanisms, in fact, has promoted a deep interest of the researchers on this topic and several modeling approaches have been developed to assess the seismic safety with respect to these mechanisms. The dynamic approach has been adopted by several authors to analyze the rocking motion of rigid blocks, under different typologies of input and boundary conditions [10]-[16]. The difficulty in defining reliable criteria of overturning under a random dynamic input has mainly been addressed with statistical methods [17],[18]; however, more recently, the reference to the worst input conditions was proposed by some authors [19]-[21] in order to identify a resonant response the blocks.

The kinematic approach, on the other hand, also represents a powerful tool to investigate the seismic capacity of masonry buildings and their vulnerability to local failure mechanisms. Force-based or displacement-based criteria can be used to describe the seismic capacity. In the former case, the horizontal force corresponding to the activation of the mechanism can be defined; in the latter case, instead, the evolution of the mechanism can be described through a relation force/displacement until the complete collapse. Both these criteria are included into the Commentaries of the last releases of the Italian Technical Standards of Constructions [22]-[25], to verify the seismic safety of existing masonry buildings. It has widely been recognized, in fact, that existing masonry buildings require a specific approach, in particular when they belong to the Cultural Heritage [26],[27].

In this paper, the kinematic approach is adopted, in the framework of the non-standard limit analysis, to evaluate the minimum load factor causing the onset of the masonry corner failure mechanism. To this aim, a macro-block model is developed, accounting for the thrusting action of the roof and the contribution of the frictional resistances. It has widely been recognized, in fact, that these resistances can play a relevant role in the seismic response of masonry structures and an increasing interest in modeling the frictional contact have promoted experimental and analytical studies [28]-[32]. However, when the frictional resistances are taken into account in the limit analysis, standard or non-standard solutions are available [33]-[37], depending on the assumed flow rule. In this paper, in particular, Coulomb frictional sliding is used, with non-associative flow rule. Moreover, a proper evaluation of the 
actual frictional resistances, involved in the combined rocking-sliding mechanism of the corner, is addressed; to this aim, the criterion proposed and validated by Casapulla et al. [8], [38]-[40] is adopted. This criterion allows calibrating the value of the frictional resistances on the basis of the inclination of the crack lines defining the macro-block; it arises from the observation that in a combined mechanism the actual value of the frictional resistances is between an upper bound related to the simple sliding mechanism and a lower bound related to the simple rocking mechanism. On the other hand, the inclination of the crack line corresponding to the maximum value tends to be vertical, while at the other extreme, it tends to the staggering ratio of units. Thus, a reduction factor of the maximum value of the frictional resistance can be defined on the basis of the actual inclination of the crack line characterizing the combined mechanism.

Hence, in Section 2, the case study building is presented, and the loading conditions together with the main geometric and mechanical data are defined. In Section 3, the analytical macro-block model and the criterion adopted to evaluate the actual contribution of the frictional resistances are described. Then, the geometry of the involved macro-block, i.e., the inclination of the main cracks, is found through the minimization condition of the load factor and finally, in Section 4, the so-obtained load factor is used to address the seismic verification in terms of ratio capacity/demand. The results obtained according to the approach of the latest two versions of the Italian Technical Standards are compared with those obtained by referring to the maximum accelerations in situ recorded.

\section{THE CASE STUDY OF A SCHOOL BUILDING IN VISSO}

The case study concerns a masonry building located in the Municipality of Visso, in the Macerata Province (Italy), strongly hit by the 2016-2017 Central Italy earthquake sequence. The building is dated back to the '30s of the last century and hosted the "Pietro Capuzi" Primary School. It is constituted by two blocks arranged in a T shape (Fig. 1a) and develops along two stories over the ground level, with a basement. The seismic events caused heavy damage to the building, with cracks affecting both masonry piers and spandrels. The present study is focused, in particular, on the out-of-plane mechanism occurred at the first storey of the north corner causing the collapse of large portions of the two orthogonal walls (Fig. 1b). The information about geometry, structural configuration and seismic damage were supplied by the Italian Network of University Laboratories in Seismic Engineering (RELUIS) and the University of Genova, in charge of post-earthquake surveys [41]. This source also provided a detailed description of the damage experienced by the building, updated on the date of December 8th, 2016.

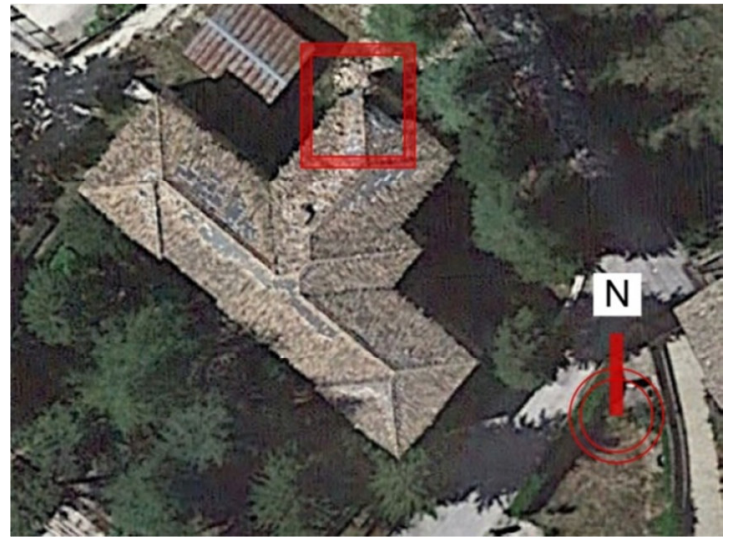

(a)

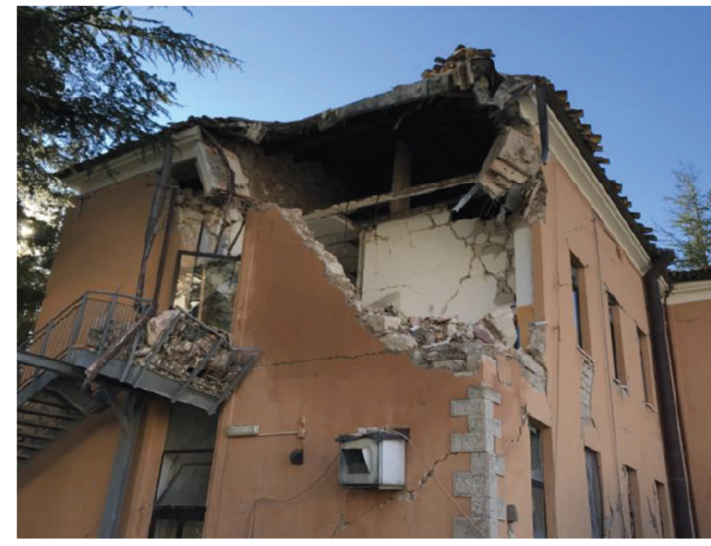

(b) 
Figure 1: Satellite view of the case study building with the identification of the corner involved in the out-ofplane mechanism (a) and view of the collapsed walls (b).

The masonry walls of the building are made out of two outer layers of split stones and a rubble inner core, defining a transversal section with thickness $s$ of about $65 \mathrm{~cm}$. The average dimensions of the stone blocks are $l_{b}=30 \mathrm{~cm}$ and $h_{b}=15 \mathrm{~cm}$, while a conventional value of the thickness $s_{b}$ are herein assumed, coincident with that related to the transversal section $\left(s_{b}=s\right)$. The blocks are arranged in a quite regular half-running bond pattern, allowing the adoption of the staggering ratio $\tan \alpha_{b}=l_{b} /\left(2 h_{b}\right)=1$. The blocks are also assembled with mortar of good quality and provide sufficient transversal connections between the outer layers and the core, exhibiting therefore a good monolithic behavior.

Fig. 2(a) schematizes the main geometric, mechanical and loading data characterizing the two orthogonal walls involved in the failure mechanism of the corner. They have the same thickness, $s$, and are denoted as Wall 1 and Wall 2, respectively oriented along the Cartesian $\mathrm{Y}$ and $\mathrm{X}$ axes. The wedge identified by the main cracks is highlighted in red color. As shown in Fig.1(b) the presence of a window on Wall 2 strongly influences the development of the cracks, which tend to localize near the vertexes of the opening, while, on the other side, a greater portion of Wall 1 is involved.

The main structure of the roof, shown in Fig. 2(b), is characterized by hip and common rafters, with purlins parallel to the perimeter walls. This constructive typology likely favored the onset of the failure mechanism of the corner; in fact, the hip rafter exerts a static thrust action on the supporting walls that is added to the inertial forces. Nevertheless, the definition of this action is an aspect poorly treated in the literature that requires rather more attention.

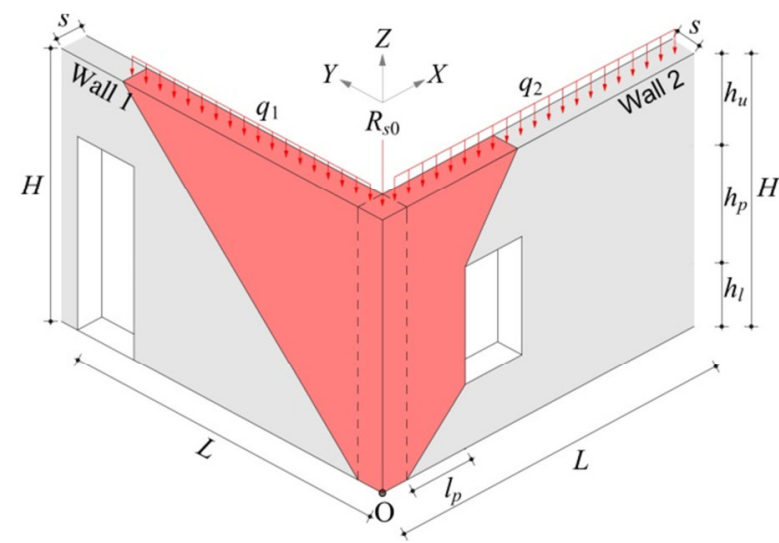

(a)

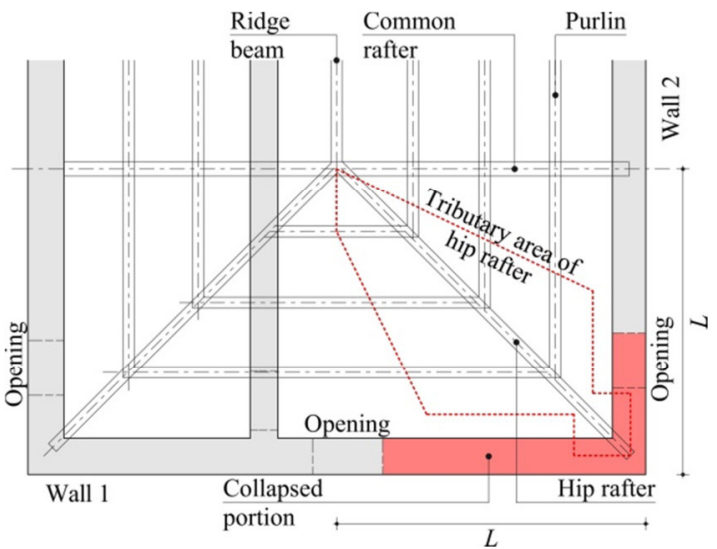

(b)

Figure 2: Axonometric view showing the geometric and loading parameters involved in the collapsed corner (a) and layout of the structure of the wooden roof $(b)$.

Thus in this paper, an isostatic scheme (Fig. 3) is used to define the vertical and horizontal static actions that the hip rafter exerts on the walls. According to this scheme, it is assumed that the action $R$ provided by the ridge beam on the hip rafter is oriented orthogonally to it. A linear distributed load, increasing towards the corner, represents the vertical load transferred by the purlins. The resultant of this load is $Q_{p}=\left(A_{p} \times W_{r}\right) / \cos \theta$, being $A_{p}$ and $W_{r}$ the tributary area and the weight of a square meter of the roof, respectively, and $\theta$ the inclination angle of pitches.

Hence, the horizontal and vertical components of the reaction $R_{s 0}$ of the hip rafter are respectively $T_{s 0}$ and $W_{s 0}$; according to the assumed static scheme they depend on the inclination $\theta$ and are expressed as: 


$$
T_{s 0}=\frac{1}{3} Q_{p} \sin \theta_{p} \cos \theta_{p} \quad W_{s 0}=Q_{p} \frac{3-\cos ^{2} \theta_{p}}{3}
$$

where $\theta_{p}$ is the inclination angle of the hip rafter:

$$
\theta_{p}=\tan ^{-1} \frac{\tan \theta}{\sqrt{2}}
$$

In Table 1 the values of the geometric, loading and mechanical data related to the case study are summarized.

\begin{tabular}{llcl}
\hline Data & & Symbol & Value \\
\hline \multirow{4}{*}{ Length of the unit block } & $l_{b}$ & $30 \mathrm{~cm}$ \\
& Height of the unit block & $h_{b}$ & $15 \mathrm{~cm}$ \\
& Staggering ratio & $\tan \alpha_{b}$ & 1 \\
& Thickness of the walls & $s$ & $65 \mathrm{~cm}$ \\
& Height of the walls & $H$ & $435 \mathrm{~cm}$ \\
& Length of the walls & $L$ & $560 \mathrm{~cm}$ \\
& Horizontal position of the window & $l_{p}$ & $155 \mathrm{~cm}$ \\
& Height of the window & $h_{p}$ & $195 \mathrm{~cm}$ \\
& Height of the spandrel under the window & $h_{l}$ & $105 \mathrm{~cm}$ \\
& Height of the spandrel over the window & $h_{u}$ & $135 \mathrm{~cm}$ \\
& Inclination angle of the pitch & $\theta$ & $21^{\circ}$ \\
& Inclination angle of the hip rafter & $\theta_{p}$ & $15^{\circ}$ \\
& Tributary area of the hip rafter & $A_{p}$ & $13.78 \mathrm{~m}$ \\
\hline Loading & Weight of a square meter of the roof & $W_{r}$ & $1.50 \mathrm{kN} / \mathrm{m}^{2}$ \\
\hline \multirow{3}{*}{ Mechanical } & $q_{1}$ & $16.16 \mathrm{kN} / \mathrm{m}$ \\
& Uniformly distributed load affecting Wall 1 & $q_{2}$ & $19.62 \mathrm{kN} / \mathrm{m}$ \\
& Uniformly distributed load affecting Wall 2 & $W_{s 0}$ & $24.29 \mathrm{kN}$ \\
& Gravity load due to the hip rafter & $T_{s 0}$ & $1.86 \mathrm{kN}$ \\
\hline & Static thrust action due to the hip rafter & $f$ & 0.6 \\
& Friction coefficient of the masonry & $\gamma$ & $21 \mathrm{kN} / \mathrm{m}^{3}$ \\
\hline \multirow{3}{*}{ Specific weight of the masonry } & &
\end{tabular}

Table 1: Geometric, loading and mechanical data of the analyzed masonry corner.

The loading condition is also characterized by the uniformly distributed loads $q_{i}(i=1,2)$ acting at the top of the walls. These take into account the gravity loads of the roof and other structural elements placed just under it: a low wall, a horizontal diaphragm with steel beams and a concrete curb. All the related loads are applied at the height of $4.35 \mathrm{~m}$ from the extrados of the first floor. It is worth noting that the greater part $(80 \%)$ of the overburden related to the diaphragm is assigned to Wall 2, because the bearing steel beams are orthogonal to this wall; moreover, the concrete curb is not considered as a restrainer the because this element was not actually effective against the rocking-sliding mechanism of the corner, as shown in Fig. 4. 


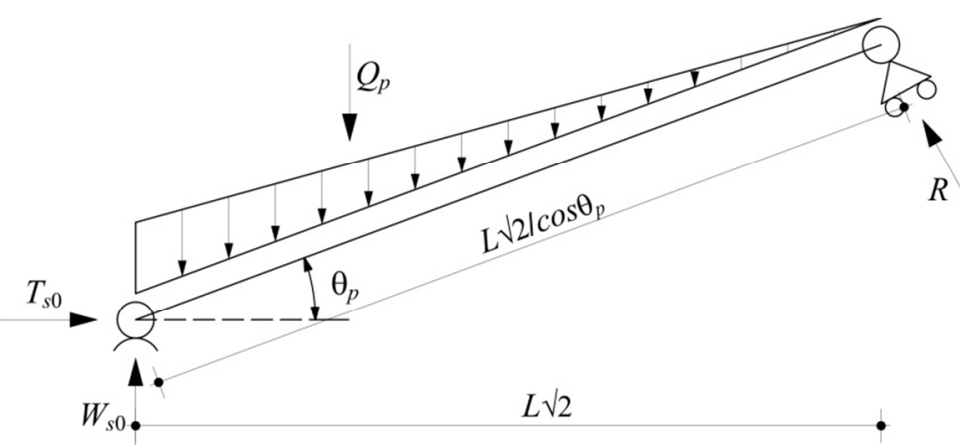

Figure 3 : Static scheme of the hip rafter.

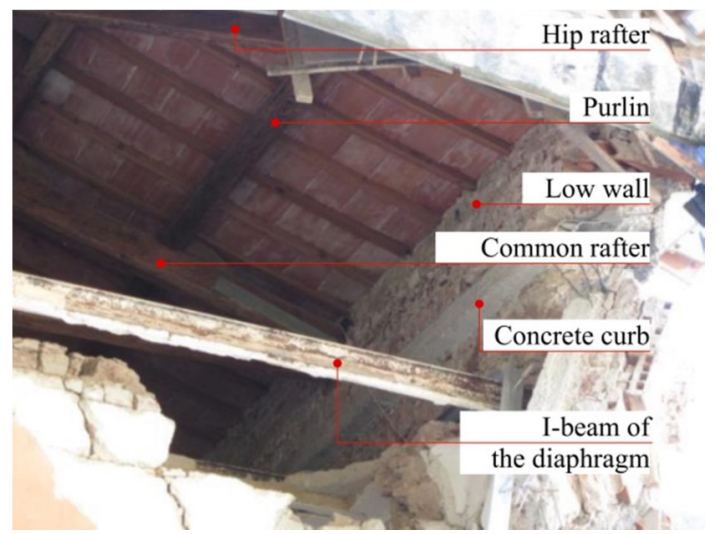

Figure 4: Roof elements and structural elements under the roof support.

\section{A MACRO-BLOCK MODEL WITH FRICTIONAL RESISTANCES FOR THE ROCKING-SLIDING MECHANISM OF THE MASONRY CORNER}

\subsection{The macro-block model}

In order to analytically investigate the onset of the failure mechanism exhibited by the masonry corner, a macro-modeling approach in the framework of the limit analysis with the kinematic method is adopted. This approach, in particular, allows evaluating the contribution of the frictional resistances in a combined rocking-sliding mechanism and was introduced and validated in some recent works by Casapulla et al. [8], [38]-[40]. According to this approach, the load factor corresponding to the onset of the mechanism and the geometry of the involved macro-block is analytically defined by imposing a minimum condition. The results allow interpreting the behavior of the case study and testing at the same time the reliability of the adopted model.

Fig. 5 represents the geometric parameters defining the macro-block together with the external and internal actions. The height of the macro-block involved in the mechanism is assumed coincident with the height $H$ of the first storey, as it actually occurred; the hinge point $\mathrm{O}$, characterizing the rocking motion of the wedge is placed on its edge. Moreover, the identification of the macro-block is based on the assumption that all the components of relative displacement between the unit blocks are concentrated along a few main cracks which affect the two sides of the corner. The inclinations of these cracks define the geometry of the mechanism. In particular, for Wall 1 a single crack with inclination angle $\beta_{1}$ is considered; on Wall 2, instead, the presence of the window causes the development of two main cracks. The inclination angle $\beta_{2 l}$ of the first crack can be identified, with good approximation, by assuming $\tan \beta_{2 l}=C_{p} / h_{l}=0.857$, being $C_{p}$ and $h_{l}$ the width of the pier and the height of the 
lower spandrel, respectively $\left(C_{p}=l_{p}-s\right.$ from Table 1$)$; the latter crack, on Wall 2, affects the upper spandrel starting approximately from the upper vertex of the window; its inclination angle $\beta_{2 u}$ together with $\beta_{1}$ represent the two unknown geometric variables of the mechanism.

It is worth noting that the non-symmetric geometry of the macro-block, due to the presence of the window on one side only, implies that the vertical plane of rotation does not coincide with the corner bisector plane; thereafter its inclination angle $\alpha$ with respect to YZ plane is dependent on the geometry of the unknown crack pattern. On the other hand, it is easy to recognize that the trace of the plane of rotation, on the XY plane, is defined by the line OG joining the hinge point $\mathrm{O}$ with the projection of the center of mass $\mathrm{G}$ on the same plane. This line also defines the direction of the horizontal forces affected by the load factor and the frictional resistances.

Finally, in Fig. 5 the length of the top rows of the two walls taking part in the mechanism is represented by the parameter $C$, i.e., $C_{1}=H \tan \beta_{1}$ and $C_{2}=C_{p}+C_{u}$ where $C_{p}=h_{l} \tan \beta_{2 l}$ and $C_{u}=h_{u} \tan \beta_{2 u}$.

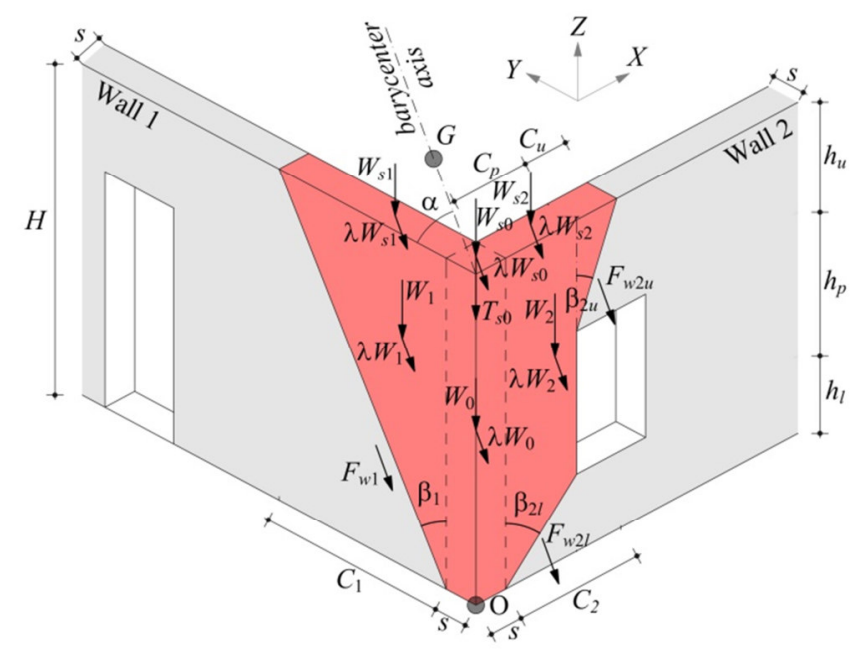

Figure 5: Axonometric view showing the external and internal loading acting on the macro-block involved in the mechanism.

\subsection{Evaluation of the frictional resistances and the load factor with the kinematic approach of the limit analysis}

The evaluation of the minimum load factor according to the kinematic approach of the limit analysis requires defining all the actions characterizing the limit condition of equilibrium of the macro-block. To this aim, with reference to the portion of interlocked walls involved in the mechanism, Table 2 reports the external and internal actions with the coordinates of their application points. The subscript " 1 " is used for the loads related to the wall along Ydirection, and " 2 " for those related the wall along X-direction. The subscript " 0 ", indicates the external loads related to the parallelepiped resulting from the intersection of the two orthogonal walls.

The external actions are the self-weights of the portions of the walls $\left(W_{0}, W_{1}, W_{2 l}, W_{2 p}\right.$, $\left.W_{2 u}\right)$, the resultants $\left(W_{s 1}, W_{s 2}\right)$ of the uniformly distributed overloads and the horizontal and vertical actions of the hip rafter previously defined, $W_{s 0}$ and $T_{s 0}$. Horizontal forces, affected by the load factor $\lambda$, are also applied to the centers of mass of all these gravity loads, to represent the inertial forces. 
The internal actions are represented by the resultants of the frictional resistances. They are taken into account under the assumption of non-associated flow rule and evaluated according to the criterion proposed and validated by Casapulla et al. [8], [38]-[40]. This criterion allows overcoming the difficulty of evaluating the actual value of the frictional resistances when a combined rocking-sliding mechanism takes place. In fact, in this case, the uplift of the unit blocks, caused by the rocking motion, implies the loss of contact along a number of interfaces which is complex to define; the value of the frictional forces, however, is expected to be lower than its maximum, $F$, corresponding to simple sliding mechanism, and at the same time greater than zero, corresponding to the case of simple rocking mechanism. Moreover, in a simple sliding mechanism, the crack line is expected to be vertical, while in a simple rocking mechanism the inclination angle of the crack line is angle $\alpha_{b}$, related to the staggering ratio of the blocks. On the basis of these considerations, a weighting criterion of the maximum frictional forces $F$ is formulated with reference to the ratio between the actual inclination angle $\beta$ of the crack line and $\alpha_{b}$. Thus, a reliable expression of the actual frictional forces $F_{w}$ in a combined rocking-sliding mechanism can be obtained through the expression:

$$
F_{w}=\left(1-\frac{\beta}{\alpha_{b}}\right) F=\omega F
$$

where the factor $\omega$ represents the rate of the maximum frictional force activated in the rocking-sliding mechanism. It is $\omega=1$ when $\beta=0$ (vertical crack line in a simple sliding mechanism) and $\omega=0$ when $\beta=\alpha_{b}$ (simple rocking mechanism). It is worth noting that, with reference to the analyzed corner, the parameter $\beta$ in Eq. (4) represents, in a compact form, the inclination angles of the crack lines related to the two walls.

Thus, in Table 2 the frictional forces $F$ are expressed in function of the number of rows crossed by the crack-lines; in particular, $n_{r}=H / h_{b}$ is the number of rows related to the whole height of the walls, while $n_{l}=h_{l} / h_{b}$ is related to the first crack-line and $n_{u}=h_{u} / h_{b}$ to the upper crack-line on Wall 2. Hence, two resultants of the frictional resistances are defined in order to take into account the effect of their different points of application on the stabilizing moments. In particular, for the two walls, the resultants $F_{w g}$ are due to the self-weight of the portion crossed by the crack-line and correspond to a linear distribution of the resistances along the height of the wall; the resultants $F_{w q}$, instead, correspond to a uniform distribution as that related to the overloading and, for Wall 2, also to the self-weight of the portion over the first crack line, whose dimensions are $C_{p} \times\left(h_{p}+h_{u}\right)$.

Once defined the forces acting on the macro-block, the application of the Principle of Virtual Work provides the expression of the load factor $\lambda$ as:

$$
\lambda=\frac{a_{1}\left(\sum_{j} W_{j} x_{j}+W_{s j} x_{s j}-0.5 \sqrt{2} T_{s 0} z_{s 0}\right)+a_{2}\left(\sum_{j} W_{j} y_{j}+W_{s j} y_{s j}-0.5 \sqrt{2} T_{s 0} z_{s 0}\right)+\sum_{j} F_{w q j} z_{q j}+\sum_{j} F_{w g j} z_{g j}}{\sum_{j} W_{j} z_{j}+W_{s j} z_{s j}}
$$

where $a_{1}=\sin \alpha$ and $a_{2}=\cos \alpha$. Recalling from Table 2 the expressions of the loading parameters in Eq. (5) it is easy to recognize that the load factor $\lambda$ depends on the unknown geometric variables $\tan \beta_{1}$ and $\tan \beta_{2 u}$. Hence, through a minimization routine, the geometry of the mechanism providing the minimum value of $\lambda$ can be defined.

The following constraints are imposed on the minimization routine:

$$
\tan \beta_{1} \leq \tan \alpha_{b} \quad \tan \beta_{2 u} \leq \tan \alpha_{b}
$$




\begin{tabular}{|c|c|c|c|}
\hline External actions & $x_{j}$ & $y_{j}$ & $z_{j}$ \\
\hline$W_{0}=\gamma s^{2} H$ & $s / 2$ & $s / 2$ & $H / 2$ \\
\hline$W_{s 0}=Q_{p} \frac{3-\cos ^{2} \theta_{p}}{3}$ & $s / 2$ & $s / 2$ & $H$ \\
\hline$W_{1}=0.5 \gamma C_{1} H s$ & $s+C_{1} / 3$ & $s / 2$ & $2 H / 3$ \\
\hline$W_{s 1}=q_{1} C_{1}$ & $s+C_{1} / 2$ & $s / 2$ & $H$ \\
\hline$W_{2 l}=0.5 \gamma C_{p} h_{l} s$ & $s / 2$ & $s+C_{p} / 3$ & $2 h_{l} / 3$ \\
\hline$W_{2 p}=\gamma C_{p}\left(h_{p}+h_{u}\right) s$ & $s / 2$ & $s+C_{p} / 2$ & $h_{l}+\left(h_{p}+h_{u}\right) / 2$ \\
\hline$W_{2 u}=0.5 \gamma C_{u} h_{u} s$ & $s / 2$ & $s+C_{p}+C_{u} / 3$ & $H-h_{u} / 3$ \\
\hline$W_{s 2}=q_{2} C_{2}$ & $s / 2$ & $s+C_{2} / 2$ & $H$ \\
\hline$T_{s 0}=\frac{1}{3} Q_{p} \sin \theta_{p} \cos \theta_{p}$ & & & $H$ \\
\hline \multicolumn{4}{|l|}{ Internal actions } \\
\hline$F_{w g 1}=\omega\left[\gamma s^{2} h_{b} \frac{n_{r}\left(n_{r}+1\right)}{2}\right] f$ & & & $H / 3$ \\
\hline$F_{w q 1}=\omega n_{r} q_{1} s f$ & & & $H / 2$ \\
\hline$F_{w g 2 l}=\omega\left[\gamma s^{2} h_{b} \frac{n_{l}\left(n_{l}+1\right)}{2}\right] f$ & & & $h_{l} / 3$ \\
\hline$F_{w q 2 l}=\omega\left[\gamma s^{2} h_{b} n_{l}\left(n_{r}-n_{l}\right)+q_{2} s n_{l}\right] f$ & & & $h_{l} / 2$ \\
\hline$F_{w g 2 u}=\omega\left[\gamma s^{2} h_{b} \frac{n_{u}\left(n_{u}+1\right)}{2}\right] f$ & & & $H-2 h_{u} / 3$ \\
\hline$F_{w q 2 u}=\omega q_{2} s n_{u} f$ & & & $H-h_{u} / 2$ \\
\hline
\end{tabular}

Table 2: External and internal actions with the coordinates of their application points.

The analytical results are summarized in Table 3 and displayed in Fig. 6. It is possible to notice that, from Eq. (4) the frictional resultants related to both the walls are null because the inclination angles of the crack lines are coincident with the angle $\alpha_{b}$ of the staggering ratio. This means that the occurred mechanism can be interpreted as simple rocking (with no sliding).

\begin{tabular}{lcc}
\hline Parameter & Label & Value \\
\hline Inclination angle of the crack line related to Wall 1 & $\beta_{1}$ & $45.00^{\circ}$ \\
Inclination angle of the crack line related to Wall 2 & $\beta_{2 u}$ & $45.00^{\circ}$ \\
Inclination angle of the plane of rotation with respect to YZ plane & $\alpha$ & $24.54^{\circ}$ \\
Minimum load factor & $\lambda$ & 0.464 \\
\hline
\end{tabular}

Table 3: Results of the limit analysis of the rocking-sliding mechanism of the masonry corner. 


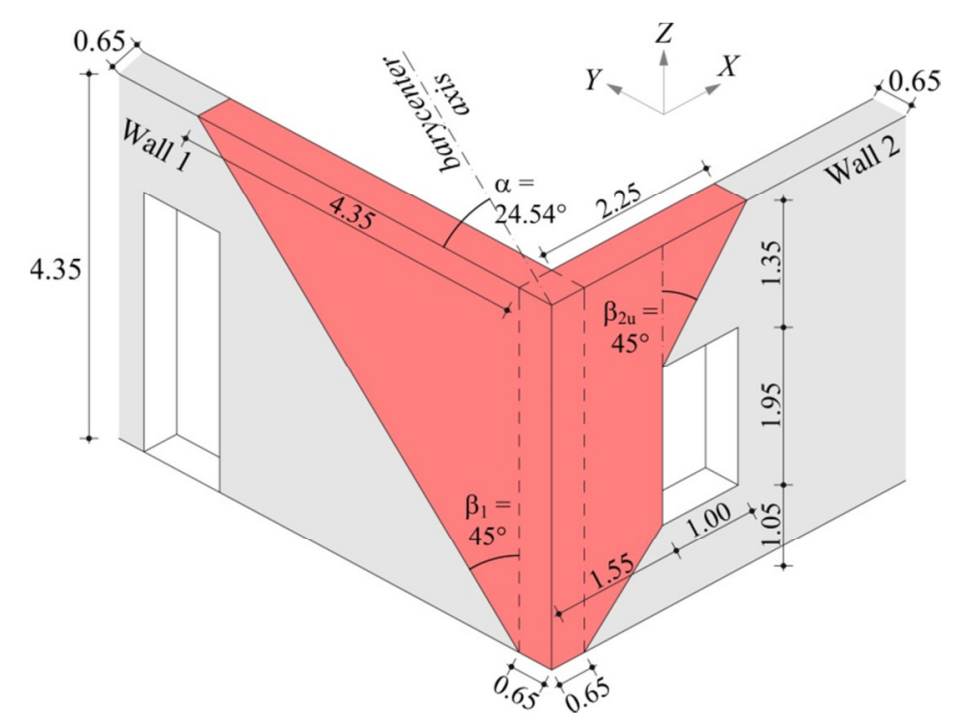

Figure 6: Axonometric view of the geometry of the mechanism resulting from the analysis (dimensions in meters).

The comparison between the geometry of the observed mechanism of the corner (Fig. 1b) and that resulting from the analytical approach (Fig. 6) confirms the reliability of the proposed model; the inclination angles of the crack lines derived from the minimization routine are very close to those actually occurred to the case study after the seismic events.

\section{SEISMIC VERIFICATION BY COMPARING CAPACITY/DEMAND}

In this section, two different approaches to the seismic verification have been compared in order to test their reliability in predicting the damage occurred to the analyzed corner, after the 2016-2017 Central Italy seismic sequence. The main difference between these approaches lies in the reference parameters defining the seismic demand, while for both of them the capacity of the structure is based on the knowledge of the load factor.

The first approach is ruled by the Italian Technical Standards of Constructions and refers to statistical parameters of seismic hazard, corresponding to a specific site and to the accepted probability of exceedance of the accounted limit state. The criteria to derive the acceleration demand from these parameters have been recently upgraded by the Commentary (CNTC18) of the current Technical Standards [25]; thereafter a useful comparison with the results provided by the Commentary (CNTC08) of the previous version of the Standards [22],[23] has also been developed.

The latter approach, on the other hand, refers to the maximum accelerations of the 20162017 seismic sequence. These data have been recorded by a number of accelerometers, placed on two orthogonal walls, at the first storey of the case study building.

\subsection{The approach of the Italian Technical Standards of Construction}

The acceleration capacity

The Commentaries of both versions of the Italian Technical Standards of Constructions define the acceleration capacity, $a_{C}$, of a local mechanism on the basis of the load factor $\lambda$ that causes its activation. The acceleration capacity taking into account the modal properties and the knowledge level is:

$$
a_{C}=\frac{\lambda g}{e^{*} \mathrm{CF}}
$$


where $g$ is the gravity acceleration, CF is a confidence factor which takes into account the available level of knowledge about the building, and $e^{*}$ is the ratio between the modal mass and the total mass of the portion involved in the mechanism.

Here, the maximum value of the confidence factor $(\mathrm{CF}=1.35)$ is prudentially assumed, according to the , while $e^{*}=0.948$. Thus, with the load factor $\lambda=0.464$ (Table 3), it is $a_{C}=3.558 \mathrm{~m} / \mathrm{s}^{2}$.

The reference parameters of seismic hazard

The two versions of the Italian Technical Standards also refer to the same parameters of seismic hazard to define the acceleration demand. They are reported in the following Table 4 for the damage limit state (DLS) and the life-safety limit state, assumed as the ultimate limit state (ULS).

\begin{tabular}{lcccc}
\hline & $T_{R}$ & $a_{g}$ & $F_{0}$ & $T_{C^{*}}$ \\
\hline DLS & 75 & 0.120 & 2.321 & 0.287 \\
ULS & 712 & 0.285 & 2.376 & 0.335 \\
\hline
\end{tabular}

Table 4: Reference parameters of seismic hazard in Visso.

In Table 4 , the parameter $T_{R}$ is the return period of the seismic action, $a_{g}$ the peak ground acceleration on a stiff soil, $F_{0}$ the factor defining the maximum amplification of the spectral accelerations and $T_{C}{ }^{*}$ corresponds to the beginning of the part of the response spectrum with constant velocity.

\section{The acceleration demand according to CNTC08}

As introduced before, the main differences between the two versions of the Technical Standards lie in the criteria defining the acceleration demand on the basis of the parameters in Table 4. According to the Commentary of the Italian Technical Standards of Constructions dated 2008 (CNTC08), the acceleration demand, $a_{D(\mathrm{CNTC} 08)}$, is defined as the maximum value between those provided by the two following expressions:

$$
a_{D(\mathrm{CNTC} 08)}=\max \left(\frac{S a_{g}}{q} ; \frac{S_{e}\left(T_{1}\right) \psi \gamma}{q}\right)
$$

where the parameter $q$ is the behavior factor of the structure and assumes the values 1 or 2 when the verification concerns the damage or the life-safety limit state respectively. It is worth noting that, according to the first expression in Eq. (8), the acceleration demand depends on the peak ground acceleration $a_{g}$ and the soil coefficient $S$, related to the topographic and stratigraphic condition. The latter expression, instead, takes into account that the hinge point of rotation of the macro-block is not placed at the ground level and an amplification effect is expected for the ground acceleration $a_{g} S$. In this case, the acceleration demand is calculated through the elastic spectral acceleration $S_{e}\left(T_{1}\right)$, corresponding to the fundamental period $T_{1}$ of the building [41],[42]. Moreover, the parameter $\psi$ is the fundamental mode shape, while $\gamma$ is the modal participation factor; they can be calculated according to the following simplified expressions:

$$
\psi=\frac{H_{\mathrm{O}}}{H_{\mathrm{tot}}} \quad \gamma=\frac{3 N}{2 N+1}
$$

where $H_{\mathrm{O}}$ is the height of the hinge point $\mathrm{O}$ of the mechanism with respect to the ground level, $H_{\text {tot }}$ is the height of the building and $N$ the number of floors. In Table 5, for each limit state, the values of the parameters required to define the acceleration demand are summarized. 


\begin{tabular}{lccccccccc}
\hline & $S$ & $T_{1}$ & $S_{e}\left(T_{1}\right)$ & $\psi$ & $\gamma$ & $q$ & $S a_{g} / q$ & $S_{e}\left(T_{1}\right) \psi \gamma / q$ & $a_{D(\mathrm{CNTC}) 8)}$ \\
& - & {$[\mathrm{s}]$} & {$\left[\mathrm{m} / \mathrm{s}^{2}\right]$} & - & - & - & {$\left[\mathrm{m} / \mathrm{s}^{2}\right]$} & $\begin{array}{c}{\left[\mathrm{m} / \mathrm{s}^{2}\right]} \\
{\left[\mathrm{m} / \mathrm{s}^{2}\right]}\end{array}$ \\
\hline DLS & 1.50 & \multirow{2}{*}{0.311} & 4.097 & \multirow{2}{*}{0.5} & 1.2 & 1 & 1.766 & 2.472 & 2.472 \\
ULS & 1.29 & & 8.589 & & & 2 & 1.809 & 2.591 & 2.591 \\
\hline
\end{tabular}

Table 5: Parameters defining the acceleration demand according to the Commentary of CNTC08.

The acceleration demand according to CNTC18

The Commentary of the current version of the Italian Technical Standards of Construction (CNTC18) defines the acceleration demand accounting for the contribution of all the meaningful modes of the building. Thus, the contribution of the $k^{\text {th }}$ mode to the maximum acceleration related to the floor with height $z$ is:

$$
a_{z k}(z)=S_{e}\left(T_{k}, \xi_{k}\right) \gamma_{k} \psi_{k}(z) \sqrt{1+0.0004 \xi_{k}^{2}}
$$

where $S_{e}\left(T_{k}, \xi_{k}\right)$ is the elastic spectral acceleration related to the $k^{\text {th }}$ mode with period $T_{k}$ and damping coefficient $\xi_{k}$ (expressed in \%), $\gamma_{k}$ is the participation factor of $k^{\text {th }}$ mode, and $\psi_{k}(z)$ is the component of the modal vector at the height $z$. It is worth noting that $S_{e}\left(T_{k}, \xi_{k}\right)$ is defined, for each limit state, on the basis of the seismic hazard parameters in Table 4. Then the acceleration demand related to the floor with height $z$ is obtained by combining the modal contributions according to the following expression:

$$
a_{D(\mathrm{CNTC} 18)}=\frac{a_{z}(z)}{q}=\frac{\sqrt{\sum\left(a_{z k}(z)\right)^{2}}}{q}
$$

where the value of the parameter $q$ depends on the reference limit state, as previously specified.

In Table 6, for each limit state, the values of the parameters required to define the acceleration demand according to CNTC18 are listed. The periods related to the first 10 mode shapes were provided by Cattari et al. [41].

\begin{tabular}{lc|cc|c|c}
\cline { 3 - 5 } & \multicolumn{2}{c}{ DLS } & \multicolumn{2}{c}{ ULS } \\
\hline$k$ & $\begin{array}{c}T_{k} \\
{[\mathrm{~s}]}\end{array}$ & $\begin{array}{c}S_{e}\left(T_{k}, \xi_{k}\right) \\
{\left[\mathrm{m} / \mathrm{s}^{2}\right]}\end{array}$ & $\begin{array}{c}a_{z k}(z) \\
{\left[\mathrm{m} / \mathrm{s}^{2}\right]}\end{array}$ & $\begin{array}{c}S_{e}\left(T_{k}, \xi_{k}\right) \\
{\left[\mathrm{m} / \mathrm{s}^{2}\right]}\end{array}$ & $\begin{array}{c}a_{z k}(z) \\
{\left[\mathrm{m} / \mathrm{s}^{2}\right]}\end{array}$ \\
\hline 1 & 0.311 & & & & \\
2 & 0.274 & & & & \\
3 & 0.266 & & & & \\
4 & 0.241 & & & & \\
5 & 0.209 & 4.097 & 2.484 & & \\
6 & 0.198 & & & & \\
7 & 0.190 & & & & \\
8 & 0.187 & & & & \\
9 & 0.180 & & & & \\
10 & 0.156 & & & & \\
\hline
\end{tabular}

Table 6: Parameters defining the acceleration demand according to CNTC18.

It is worth noting that the parameters $\psi_{k}(z)$ and $\gamma_{k}$ in Eq. (10) have been calculated with Eq. (9) and thereafter they assume the same values for all the modes. Moreover, the value of the conventional viscous damping is $\xi_{k}=5$, for all the modes. 


\section{The comparison capacity/demand}

The results of the seismic verification according to the current and previous versions of the Italian Technical Standards are summarized in the following Table 7. They are expressed in terms of ratio capacity/demand $\left(a_{C} / a_{D}\right)$ for each limit state.

\begin{tabular}{cccccc}
\hline & \multicolumn{2}{c}{ Demand } & Capacity & DLS & ULS \\
\cline { 2 - 6 } & $a_{D, \mathrm{DLS}}$ & $a_{D, \mathrm{ULS}}$ & $a_{C}$ & $a_{C} / a_{D, \mathrm{DLS}}$ & $a_{C} / a_{D, \mathrm{ULS}}$ \\
& {$\left[\mathrm{m} / \mathrm{s}^{2}\right]$} & {$\left[\mathrm{m} / \mathrm{s}^{2}\right]$} & {$\left[\mathrm{m} / \mathrm{s}^{2}\right]$} & - & - \\
\hline CNTC08 & 2.472 & 2.591 & 3.558 & 1.439 & 1.373 \\
CNTC18 & 4.303 & 4.511 & 3.558 & 0.827 & 0.789 \\
\hline
\end{tabular}

Table 7: Ratios capacity/demand provided by the two versions of the Italian Technical Standards.

In particular, the demand obtained according to the current version is defined by considering the first three modes of vibration as the most meaningful ones, to take into account the translational modes in both orthogonal directions (modes 1 and 3 ) and the torsional mode (mode 2) mainly affecting the 3D failure mechanism.

It arises that the results provided by the previous version of the Italian Technical Standards are not consistent with the actual damage suffered by the masonry corner. In fact, for both the accounted limit states, the acceleration capacity of the mechanism is greater than the seismic demand $\left(a_{C} / a_{D}>1\right)$. The improvement of the criteria defining the seismic demand, introduced by the current version of the Italian Technical Standards, instead, implies that the seismic verification is not satisfied, for both limit states. Moreover, this result is confirmed by the collapse of the masonry corner, actually occurred.

\subsection{The approach based on the in situ recorded maximum floor accelerations}

In this section, the seismic verification of the corner under study is developed, by assuming as seismic demand the maximum floor accelerations, in situ recorded. In fact, before the 2016-2017 seismic events, a monitoring study of the building was implemented by means of axial and bi-axial accelerometers positioned at different levels of the structure by the Seismic Observatory of Structures (OSS) [43]. In particular, a bi-axial accelerometer was placed on the adjacent corner at the level of the first floor of the building (i.e. at the height of the hinge point of the mechanism) and its recorded inputs are used in this analysis in place of the records on the ground.

Thus, considering the main four earthquakes of the whole 2016-2017 seismic sequence, the maximum accelerations registered for each record and for $\mathrm{X}$ and $\mathrm{Y}$ directions (Fig. 2) are reported in Table 8 . These accelerations take into account implicitly both the effects of the soil features and the amplification due to the position of the hinge point with respect to the ground. Therefore, they can directly represent the seismic demand.

In order to define the acceleration capacity of the mechanism related to $\mathrm{X}$ and $\mathrm{Y}$ directions, the components of the load factor on these axes are calculated, while the same value of the mass participating to the mechanism, $e^{*}=0.948$, is assumed. The two components are:

$$
a_{C x}=\frac{\lambda g}{e^{*}} \sin \alpha \quad a_{C x}=\frac{\lambda g}{e^{*}} \cos \alpha
$$

It is worth noting that the acceleration capacities in Eq. (12) does not account for the confidence factor, because the seismic verification, in this case, is not ruled by the Technical Standards. Hence in Table 8, the comparison capacity/demand is reported for each record and direction. 


\begin{tabular}{clcccccc}
\hline \multirow{2}{*}{$\begin{array}{l}\text { ID } \\
\text { record }\end{array}$} & Date & \multicolumn{2}{c}{ Demand } & \multicolumn{2}{c}{ Capacity } & \multicolumn{2}{c}{ Capacity/Demand } \\
\cline { 2 - 7 } & $\begin{array}{c}a_{D x} \\
{\left[\mathrm{~m} / \mathrm{s}^{2}\right]}\end{array}$ & $\begin{array}{c}a_{D y} \\
{\left[\mathrm{~m} / \mathrm{s}^{2}\right]}\end{array}$ & $\begin{array}{c}a_{C x} \\
{\left[\mathrm{~m} / \mathrm{s}^{2}\right]}\end{array}$ & $\begin{array}{c}a_{C y} \\
{\left[\mathrm{~m} / \mathrm{s}^{2}\right]}\end{array}$ & $\begin{array}{c}a_{\mathrm{Cx}} / a_{\mathrm{Dx}} \\
-\end{array}$ & $\begin{array}{c}a_{\mathrm{C} y} / a_{\mathrm{D} y} \\
-\end{array}$ \\
\hline 1 & $24 / 08 / 2016$ & 5.660 & 6.004 & & & 0.352 & 0.728 \\
2 & $\begin{array}{l}26 / 10 / 2016 \text { (h } 5.10 \\
\mathrm{pm})\end{array}$ & 4.640 & 5.376 & & & 0.430 & 0.813 \\
3 & $\begin{array}{l}26 / 10 / 2016 \text { (h } 7.18 \\
\text { pm) }\end{array}$ & 4.326 & 5.994 & & & 0.461 & 0.729 \\
4 & 30/10/2016 & 4.562 & 6.690 & & & 0.437 & 0.653 \\
\hline
\end{tabular}

Table 8: Recorded maximum accelerations related to X and Y directions. Ratios capacity/demand

Table 8 shows that the ratios capacity/demand, related to all records and directions, do not meet the seismic verification. In particular, $\mathrm{X}$ direction is more vulnerable than $\mathrm{Y}$ direction, being the ratios $a_{C x} / a_{D}$ always lower than $a_{C y} / a_{D}$ for each record. This circumstance, on the other hand, can be explained probably by the non-symmetric geometry of the macro-block involved in the mechanism. In fact, the presence of the window on the wall along the $X$ direction (Wall 2) influences the position of the center of mass of the macro-block, that is very close to the Y direction (see Fig. 6). Thus the macro-block has higher inertial capacity in the $\mathrm{Y}$ direction, while it is extremely vulnerable in the $\mathrm{X}$ direction.

\section{CONCLUSIONS}

In this paper, the rocking-sliding mechanism of a masonry corner has been analytically investigated, by referring to a case study located in Visso (Italy), strongly damaged by the 2016-2017 Central Italy earthquake. This type of mechanism is frequently observed at the top level of masonry buildings mainly when the roof is composed by thrusting elements, or there are openings very close to the corner. The load factor corresponding to the onset of the mechanism has been evaluated by adopting the kinematic approach of the limit analysis, also accounting for the influence of the static thrust of the roof and the contribution of the frictional resistances. In particular, a reliable criterion, proposed and validated in previous works, has been adopted to assess the actual value of the frictional resistances in the combined rocking-sliding mechanism. The geometry of the involved macro-block has also been defined through the inclinations of two main cracks affecting the interlocked walls. They have been analytically obtained by imposing a minimization condition on the load factor. The resulting geometry confirms the reliability of the proposed model; in fact, the inclination angles of the crack lines, derived from the analysis, are very close to those actually occurred to the case study.

Then, on the basis of the load factor, the acceleration capacity of the mechanism has been obtained, and the seismic verification has been addressed in terms of ratio capacity/demand. The comparison of different approaches in evaluating the seismic demand has highlighted interesting issues. In particular it has emerged that the criteria proposed by the Commentary (CNTC08) of the previous version of the Italian Technical Standards are not effective in predicting the acceleration demand; in fact, the value obtained is higher than the capacity and clearly not consistent with the damage actually suffered by the building. The Commentary (CNTC18) of the current version of the Italian Technical Standards, instead, has improved these criteria, accounting for the contribution of all the meaningful modes of the building. Thus, the maximum acceleration expected at the level of the center of rotation of the mechanism results greater than the capacity for all the reference limit states. Finally, a seismic verification has also been carried out by assuming, as representative of the seismic demand, the maximum in situ recorded accelerations, related to the 2016-2017 seismic sequence. The 
non-symmetric geometry of the macro-block implies that the capacity related to the $\mathrm{X}$ direction is lower than that related to Y. In fact, the presence of the window on the wall along the $\mathrm{X}$ direction influences the position of the center of mass of the macro-block, that is very close to the $\mathrm{Y}$ direction; as a consequence, higher inertial capacity characterizes the $\mathrm{Y}$ direction, while the $\mathrm{X}$ direction is extremely vulnerable.

In conclusion, one has to observe that the seismic verification has been carried out in this paper through a force-based approach, but a full investigation of the evolution of the mechanism would require a non-linear kinematic analysis, that, however, will be developed in future works.

\section{REFERENCES}

[1] V. Alecci and M. De Stefano, Building irregularity issues and architectural design in seismic areas. Frattura ed Integrità Strutturale, 13, 161-168, 2019.

[2] V. Alecci, M. De Stefano, S. Galassi, M. Lapi, and M. Orlando, Evaluation of the American Approach for Detecting Plan Irregularity. Advances in Civil Engineering, 2019.

[3] D. D'Ayala, E. Speranza, Definition of collapse mechanisms and seismic vulnerability of historic masonry buildings. Earthquake Spectra, 19, 479-509, 2003.

[4] M. Sassu, M. Andreini, C. Casapulla, A. De Falco, Archaeological consolidation of UNESCO masonry structures in Oman: the Sumhuram Citadel of Khor Rori and the AlBalid Fortress. International Journal of Architectural Heritage, 7(4), 339-74, 2013.

[5] M. Andreini, A. De Falco, L. Giresini, M. Sassu, Collapse of the historic city walls of Pistoia (Italy): Causes and possible interventions. Applied Mechanics and Materials, 351-352, 2013.

[6] L. Giresini, M. Sassu, C. Butenweg, V. Alecci, M. De Stefano, Vault macro-element with equivalent trusses in global seismic analyses. Earthquake and Structures, 12, 409423, 2017.

[7] C. Casapulla, A. Maione, Experimental and analytical investigation on the corner failure in masonry buildings. Interaction between rocking-sliding and horizontal flexure. International Journal of Architectural Heritage, 1-13, 2018.

[8] C. Casapulla, A. Maione, L. U. Argiento, E. Speranza, Corner failure in masonry buildings: An updated macro-modeling approach with frictional resistances. European Journal of Mechanics-A/Solids, 70, 213-225, 2018.

[9] L. Giresini, M. Fragiacomo, M. Sassu, Rocking analysis of masonry walls interacting with roofs. Engineering Structures, 116, 107-120, 2016.

[10] F. Peña, P. B. Lourenço, J. V. Lemos, Modeling the dynamic behavior of masonry walls as rigid blocks. In III European Conference on Computational Mechanics, Springer Netherlands, 2008.

[11] K. Nabeshima, R. Taniguchi, K. Kojima, I. Takewaki, Closed-form overturning limit of rigid block under critical near-fault ground motions. Frontiers in Built Environment, 2(9), 2016.

[12] U. Andreaus, P. Casini, On the rocking-uplifting motion of a rigid block in free and forced motion: influence of sliding and bouncing. Acta Mechanica, 138, 219-241, 1999. 
[13] J. Zhang, N. Makris, Rocking response of free-standing blocks under cycloidal pulses. Journal of Engineering Mechanics, 127(5), 473-483, 2001.

[14] L. Giresini, M. Sassu, Horizontally restrained rocking blocks: evaluation of the role of boundary conditions with static and dynamic approaches. Bulletin of Earthquake Engineering, 15, 385-410, 2017.

[15] L. Giresini, M. Sassu, and L. Sorrentino, In situ free-vibration tests on unrestrained and restrained rocking masonry walls. Earthquake Engineering \& Structural Dynamics, 47, 3006-3025, 2018.

[16] C. Casapulla, L. Giresini, P. B. Lourenço, Rocking and kinematic approaches for rigid block analysis of masonry walls: state of the art and recent developments. Buildings, 7 , 2017.

[17] E. G. Dimitrakopoulos, T. S. Paraskeva, Dimensionless fragility curves for rocking response to near-fault excitations. Earthquake Engineering \& Structural Dynamics, 44(12), 2015-2033, 2015.

[18] L. Giresini, C. Casapulla, R. Denysiuk, J. Matos, M. Sassu, Fragility curves for free and restrained rocking masonry façades in one-sided motion. Engineering Structures, 164, 195-213, 2018.

[19] C. Casapulla, On the resonance conditions of rigid rocking blocks. International Journal of Engineering and Technology. 7(2), 760-761, 2015.

[20] C. Casapulla, A. Maione, Critical response of free-standing rocking blocks to the intense phase of an earthquake. International Review of Civil Engineering, 8, 2017.

[21] M. J. DeJong, Amplification of rocking due to horizontal ground motion. Earthquake Spectra, 28(4), 1405-1421, 2012.

[22] (NTC08) Ministero delle Infrastrutture e dei trasporti, D.M. 14.01.2008 Approvazione delle nuove norme tecniche per le costruzioni. Suppl. Ord. No. 30 alla Gazzetta Ufficiale No. 29 del 04/2/2008. (in Italian)

[23] (CNTC08) Ministero delle Infrastrutture e dei trasporti, Circolare 2 febbraio 2009, n. 617 C.S.LL.PP., Istruzioni per l'applicazione delle "Nuove norme tecniche per le costruzioni" di cui al decreto ministeriale 14 gennaio 2008. Suppl. Ord. No. 27 alla Gazzetta Ufficiale No. 47 del 26/02/2009. (in Italian)

[24] (NTC18) Ministero delle Infrastrutture e dei trasporti, D.M. 17.01.2018, Aggiornamento delle "Norme tecniche delle costruzioni". Suppl. Ord. No. 8 alla Gazzetta Ufficiale No. 42 del 20/2/2018. (in Italian)

[25] (CNTC18) Ministero delle Infrastrutture e dei trasporti, Circolare 21 gennaio 2019, n. 7 C.S.LL.PP., Istruzioni per l'applicazione dell"'Aggiornamento delle "Norme tecniche per le costruzioni" di cui al decreto ministeriale 17 gennaio 2018. Suppl. Ord. No. 5 alla Gazzetta Ufficiale No. 35 del 11/2/2019. (in Italian).

[26] C. Casapulla, A. Maione, L. U. Argiento, Seismic analysis of an existing masonry building according to the multi-level approach of the Italian guidelines on Cultural Heritage. Ingegneria Sismica Italiana (International Journal of Earthquake Engineering), 34(1), 40-59, 2017.

[27] C. Casapulla, L. U. Argiento, A. Maione, Seismic safety assessment of a masonry building according to Italian Guidelines on Cultural Heritage: simplified mechanical- 
based approach and pushover analysis. Bulletin of Earthquake Engineering, 16(7), 2809-2837, 2018.

[28] A. Orduña, P. B. Lourenço, Three-dimensional limit analysis of rigid blocks assemblages. Part I: Torsion failure on frictional interfaces and limit analysis formulation. International Journal of Solids and Structures, 42(18-19), 5140-5160, 2005.

[29] C. Casapulla, A. Maione, Formulating the torsion strength of dry-stacked stone blocks by comparing convex and concave contact formulations and experimental results. Indian Journal of Science and Technology, 9(46), 1-7, 2016.

[30] C. Casapulla, F. Portioli, Experimental tests on the limit states of dry-jointed tuff blocks. Materials and Structures, 49(3), 751-67, 2016.

[31] J.V. Lemos, Contact representation in rigid block models of masonry. International Journal of Masonry Research and Innovation, 2(4), 321-334, 2017.

[32] C. Casapulla, A. Maione, Modelling the dry-contact interface of rigid blocks under torsion and combined loadings: Concavity vs. convexity formulation. International Journal of Non-Linear Mechanics, 99, 86-96, 2018.

[33] D.C. Drucker, Coulomb friction, plasticity and limit loads. (No. TR-85). Brown Univ. Providence Ri. Div. of Applied Mathematics, 1953.

[34] R.K. Livesley, Limit analysis of structures formed from rigid blocks. International Journal for Numerical Methods in Engineering, 12, 1853-71, 1978.

[35] M. Como, Equilibrium and collapse analysis of masonry bodies. Meccanica, 27(3), 18594, 1992.

[36] M. Gilbert, C. Casapulla, and H. M. Ahmed, Limit analysis of masonry block structures with non-associative frictional joints using linear programming. Computers \& Structures, 84(13-14), 873-887, 2006.

[37] L.U. Argiento, A. Maione, C. Casapulla, Formulating the in-plane frictional resistances and collapse mechanisms for multi-storey masonry block walls. Fracture and Structural Integrity, 12(46), 226-239, 2018.

[38] C. Casapulla, F. Portioli, A. Maione, and R. Landolfo, A macro-block model for inplane loaded masonry walls with non-associative Coulomb friction. Meccanica, 48(9), 2107-2126, 2013.

[39] C. Casapulla, L. U. Argiento, The comparative role of friction in local out-of-plane mechanisms of masonry buildings. Pushover analysis and experimental investigation. Engineering Structures, 126, 158-173, 2016.

[40] C. Casapulla, L. U. Argiento, In-plane frictional resistances in dry block masonry walls and rocking-sliding failure modes revisited and experimentally validated. Composites Part B Engineering, 132, 197-213, 2017.

[41] S. Cattari, S. Degli Abbati, D. Ottonelli, D. Sivori, E. Spacone, G. Camata et al., Task 4.1 Workgroup_Report di sintesi sulle attività svolte sugli edifici in muratura monitorati dall'Osservatorio Sismico delle Strutture, Linea Strutture in Muratura. ReLUIS Report, Rete Dei Laboratori Universitari Di Ingegneria Sismica, 2017. (in Italian) 
[42] C. Ferrero, P.B. Lourenço, C. Calderini, 2016-2017 Central Italy Earthquake: Seismic assessment of "Pietro Capuzi" School in Visso (Marche). $9^{\text {th }}$ International Conference on Computational Methods (ICCM2018), Roma, Italy, August 6-10, 2018.

[43] DPC. Osservatorio Sismico delle Strutture OSS Download Service. http://www.mot1.it/ossdownload. 